\title{
Gut Microbiome-based Therapeutics in Liver Cirrhosis: Basic Consideration for the Next Step
}

\author{
Hiroshi Fukui* \\ Department of Gastroenterology, Endocrinology and Metabolism, Nara Medical University, Kashihara, Japan
}

\begin{abstract}
Infections account for significant morbidity and mortality in liver cirrhosis and most are related to the gut microbiome. Fecal dysbiosis, characterized by an overgrowth of potentially pathogenic bacteria and a decrease in autochthonous nonpathogenic bacteria, becomes prominent with the progression of liver cirrhosis. In cirrhotic patients, disruption of the intestinal barrier causes intestinal hyperpermeability (i.e. leaky gut), which is closely related to gut dysmotility, dysbiosis and small intestinal bacterial overgrowth and may induce pathological bacterial translocation. Although the involved microbial taxa are somewhat different between the cirrhotic patients from the East and the West, the common manifestation of a shortage of bacteria that contribute to the production of short-chain fatty acids and secondary bile acids may facilitate intestinal inflammation, leaky gut and gut dysbiosis. Translocated endotoxin and bacterial DNA are capable of provoking potent inflammation and affecting the metabolic and hemodynamic systems, which may ultimately enhance the progression of liver cirrhosis and its various complications, such as hepatic encephalopathy $(\mathrm{HE})$, variceal bleeding, infection and renal disturbances. Among studies on the microbiome-based therapeutics, findings of probiotic effects on HE have been contradictory in spite of several supportive results. However, the effects of synbiotics and prebiotics are substantially documented. The background of their effectiveness should be evaluated again in relation to the cirrhosis-related changes in gut microbiome and their metabolic effects. Strict indications for the antibiotic rifaximin remain unestablished, although its effect is promising, improving $\mathrm{HE}$ and other complications with little influence on microbial populations. The final goal of microbiome-based therapeutics is to adjust the gut-liver axis to the maximal
\end{abstract}

Keywords: Liver cirrhosis; Dysbiosis; Endotoxemia; Therapeutics.

Abbreviations: AKI, acute kidney injury; BA, bile acid; $B T$, bacterial translocation; $C A$, cholic acid; CDCA, chenodeoxycholic acid; CDR, cirrhosis dysbiosis ratio; CYP, cytochrome P450; DCA, deoxycholic acid; FOS, fructo-oligosaccharides; GABA, $\gamma$-aminobutyric acid; GOS, galacto-oligosaccharides; HE, hepatic encephalopathy; HBV, hepatitis B virus; $\mathrm{HCV}$, hepatitis $\mathrm{C}$ virus; $\mathrm{HRS}$, hepatorenal syndrome; IFN, interferon; IL, interleukin; LCA, lithocholic acid; LAL, limulus amebocyte lysate; MELD, model for end-stage liver disease; MHE, minimal hepatic encephalopathy; MLNs, mesenteric lymph nodes; NO, nitric oxide; OCTT, orocecal transit time; PBMCs, peripheral blood mononuclear cells; RCTs, randomized controlled trials; SCFAs, short-chain fatty acids; SIBO, small intestinal bacterial overgrowth; SBP, spontaneous bacterial peritonitis; SID, selective intestinal decontamination; TJ, tight junction; TNF, tumor necrosis factor; TLR, Toll-like receptor. Received: 26 January 2017; Revised: 24 April 2017; Accepted: 11 May 2017 * Correspondence to: Hiroshi Fukui, Department of Gastroenterology, Endocrinology and Metabolism, Nara Medical University, 840 Shijo-cho Kashihara, 634-8522 Nara, Japan. Tel: +81-744223051, E-mail: hfukui@naramed-u.ac.jp benefit of cirrhotic patients, with the aid of evolving metagenomic and metabolomic analyses.

Citation of this article: Fukui $\mathrm{H}$. Gut microbiome-based therapeutics in liver cirrhosis: basic consideration for the next step. J Clin Transl Hepatol 2017;5(3):249-260. doi: 10.14218/JCTH.2017.00008.

\section{Introduction}

Liver cirrhosis is a consequence of long-lasting chronic liver diseases and is characterized by liver fibrosis and portal hypertension. Prognosis of patients with liver cirrhosis is affected by such serious complications as gastroesophageal varices, ascites, hepatic encephalopathy $(\mathrm{HE})$ and renal disturbances, all of which are related to portal hypertension, hyperdynamic circulation and metabolic disorders. ${ }^{1}$ Bacterial infections including spontaneous bacterial peritonitis (SBP) account for significant morbidity and mortality, ${ }^{2}$ for which gut bacteria are commonly involved as the pathogenic factors.

Disruption of the intestinal barrier induces the passage of bacteria and their products from the intestinal lumen, thereby evoking potent inflammatory reactions, inducing various infections, and affecting portal and systemic circulations. Intestinal dysfunction, gut dysbiosis and endotoxin (i.e. lipopolysaccharide) from Gram-negative bacteria are key players in these processes. They provoke inflammatory changes in the liver and various extrahepatic sites, facilitating the progression of liver cirrhosis and the development of cirrhotic complications.

Various microbiome-based therapeutics, such as probiotics, prebiotics, synbiotics and antibiotics, have been applied for the management of $\mathrm{HE}$ and other complications. Recent progress in metagenomic and metabolomic analyses, however, have shed light on the mechanisms of the gut-liver axis derangement and also on the action mechanisms of these microbiomebased therapeutics. This review summarizes the derangement of gut-liver axis related to gut dysbiosis and the recent progress in microbiome-based therapeutics.

\section{Changes in gut microbiome}

Patients with liver cirrhosis frequently exhibit small intestinal bacterial overgrowth (SIBO). ${ }^{3}$ This condition is closely related to delayed intestinal transit and has some impact on the development of cirrhotic complications. In addition, marked alteration of the intestinal microbiome (i.e. dysbiosis) has been noted in these patients. ${ }^{4}$ 


\section{Gut dysbiosis and its clinical implications}

Non-culture methods, such as pyrosequencing analysis of fecal contents, have revealed reduced gut microbial diversity and marked dysbiosis in patients with liver cirrhosis. ${ }^{5}$ The known changes in intestinal microbiota and their possible relations to intestinal dysfunction, bacterial translocation and cirrhotic complications are summarized in Fig. 1 (Fig. 1A: based on the microbial data from the China; Fig. 1B: based on the microbial data from the USA).

Chen et $a .^{5}$ reported that the proportion of phylum Bacteroidetes was decreased, although Proteobacteria and Fusobacteria were highly enriched, in feces of Chinese patients with cirrhosis associated with hepatitis B virus (HBV) infection and alcohol drinking. Their recent study ${ }^{6}$ further showed a decrease of the genera Eubacterium, Bacteroides and Alistipes and an increase of the genera Veillonella, Clostridium, Streptococcus, and Prevotella. Among the 20 species with the highest increases, 6 were Veillonella spp. and 4 were Streptococcus spp., indicating that these two genera might play a cardinal role in liver cirrhosis. Yet another study from this Chinese group ${ }^{7}$ showed that patients with HBV-related cirrhosis exhibited decreases in Faecalibacterium prausnitzii, Bifidobacterium, and Clostridium and increases in Enterobacteriaceae and Enterococcus faecalis. Faecalibacterium prausnitzii is an anti-inflammatory bacterium that stimulates interleukin (IL) -10 secretion and inhibits IL- 12 and interferon-gamma expressions. ${ }^{8}$ They further noted a decrease in Bifidobacterium, especially Bifidobacterium catenulatum, in the feces of HBVrelated cirrhotics, ${ }^{9}$ and a marked decrease in Lactobacillus rhamnosus and a reduction in Lactobacillus fermentus in the feces of patients with decompensated cirrhosis ${ }^{10}$ (Fig. 1A).

On the other hand, Bajaj et al. ${ }^{11}$ reported that fecal microbiota in patients from the United States with alcohol-related and hepatitis $\mathrm{C}$ virus (HCV)-related liver cirrhosis had a lower proportion of Ruminococcaceae and Lachnospiraceae and a higher proportion of Alcaligeneceae, Enterobacteriaceae, and Fusobacteriaceae (Fig. 1B).

Ruminococcaceae, Lachnospiraceae and Faecalibacterium prausnitzii are butyrate-producing bacteria. Butyrate, as a representative short-chain fatty acid (SCFA), is a significant source of energy for enterocytes, and influences the intestinal barrier function through the stimulation of tight junctions and mucous production. ${ }^{12-14}$ SCFAs are known to maintain normal colonocyte turnover, to increase anti-bacterial peptides (LL-37 and CAP-18) and to reduce colonic inflammation. ${ }^{14,15}$ They have various anti-inflammatory effects on the innate and adaptive immune systems, suppressing inflammatory cytokine production, inhibiting immune cell maturation and recruitment, and inducting regulatory T cells. ${ }^{15,16}$

The cirrhosis dysbiosis ratio (CDR) proposed by Bajaj et $a .^{17}$ consists of the amounts of beneficial autochthonous taxa (Lachnospiraceae + Ruminococaceae + Veillonellaceae + Clostridiales Incertae Sedis XIV) and potentially pathogenic taxa (Enterobacteriaceae + Bacteroidaceae), reflecting changes in the "good" versus "bad" bacteria in the intestine of cirrhotic patients. The CDR was found to be negatively correlated to the model of end-stage liver disease (MELD) score as well as the blood endotoxin level. ${ }^{17} \mathrm{~A}$ low CDR was also found to be associated with death and organ failure within 30 days. $^{17}$

\section{Intestinal mucosal dysbiosis}

Bajaj et al. ${ }^{18}$ examined the rectosigmoidal mucosal microbiome in addition to the fecal microbiome, as the former may reflect the intestinal barrier condition more precisely. The rectosigmoidal mucosal microbiome in cirrhotic patients showed a lower abundance of autochthonous bacteria (Subdoligranulum, Dorea, and Incertae Sedis XIV other) and a higher abundance of potentially pathogenic bacteria (Enterococcus, Clostridium, Burkholderia, and Proteus) compared with healthy controls ${ }^{18}$ (Fig. 1B). Chen et al. ${ }^{19}$ recently examined the duodenal mucosal microbe and reported that Veillonella, Megasphaera, Dialister, Atopobium and Prevotella were increased in cirrhotic patients, and that Neisseria, HaemophiIUS and SR1 genera incertae sedis were enriched in healthy controls. All these taxa are commonly found in the oral cavity, suggesting a great impact of oral microbiota on duodenal microbiota $^{19}$ (Fig. 1A).

\section{Oral dysbiosis}

Dysbiosis with reduced autochthonous taxa is found in saliva of cirrhotic patients, especially those with previous history of $\mathrm{HE}$ or hospitalizations. ${ }^{20}$ Qin et $a l .{ }^{6}$ reported that a majority of bacteria found in the feces of cirrhotic patients was of buccal origin, suggesting invasion of the gut by oral bacterial species. Interestingly, the above-mentioned, presumably pathogenic Streptococcus spp. and Veillonella spp. are considered to be of oral origin. ${ }^{6}$ The invading bacteria, foreign to the niche, are found not only in the colon but also in the ileum and duodenum, which provoke SIBO in patients with liver cirrhosis. ${ }^{6}$ The mechanism of this invasion is not yet fully understood, but may be related to impaired bile acid (BA) and gastric acid output in cirrhosis. $^{21}$

Metabolic changes related to gut dysbiosis

\section{BAs and gut dysbiosis}

Lower abundance of $7 \alpha$-dehydroxylating bacteria (Lachonospiraceae, Ruminococcaceae and Blautia) were reported as present in the stools of cirrhotics. ${ }^{22}$ These bacteria convert primary BAs, chenodeoxycholic acid (CDCA) and cholic acid (CA) into secondary BAs, lithocholic acid (LCA) and deoxycholic acid (DCA), respectively (Fig. 1B). The abundances of Ruminococcaceae and Blautia were found to be positively correlated to DCA/CA and LCA/CDCA, respectively, suggesting that a reduced conversion of primary to secondary BAs was linked with an abundance of key gut microbiome constituents.

Secondary BAs have membrane destabilizing actions, both on the microbiome and on the gut epithelium. ${ }^{23,24}$ It is not evident at present if this reduction in secondary BAs is either a cause of overgrowth of pathogenic bacteria $^{25,26}$ or a result of an adaptation to prevent gut epithelial disruption in liver cirrhosis. ${ }^{22}$ BT-induced inflammation suppresses the synthesis of total BAs by inhibiting CYP7A1 in the liver (Fig. 1A, 1B). BAs prevent bacterial translocation (BT) and inhibit the passage of microbial products from the intestinal lumen. ${ }^{27} \mathrm{~A}$ decrease in BAs entering the intestines is thus considered to favor overgrowth of pathogenic microbiome constituents, including Enterobacteriaceae and Porphyromonadaceae, in liver cirrhosis. ${ }^{28}$ 
Fukui H.: Microbiome-based therapeutics in cirrhosis
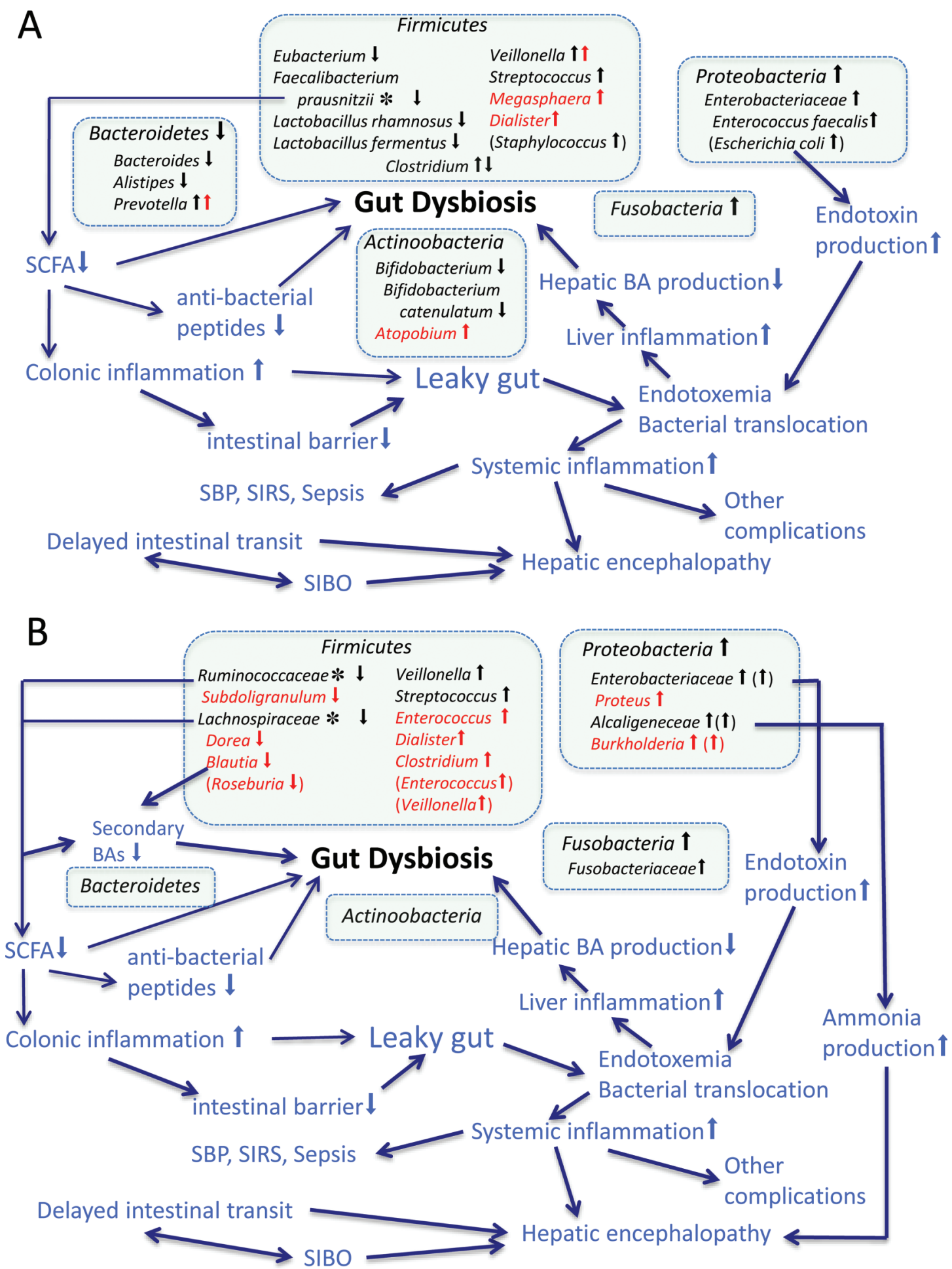

Fig. 1. Changes in intestinal microbiota and the possible relations to intestinal dysfunction, bacterial translocation, and cirrhotic complications in cirrhosis. The microbial data in the Chinese studies (A) and American studies (B) are different, although there are several common findings. Both reported a higher proportion of Enterobacteriaceae, potentially pathogenic bacteria producing potent endotoxin. The decreases in butyrate-producing bacteria Faecalibacterium prausnitzii (A*), Ruminococcaceae and Lachnospiraceae (B*) result in a decrease in anti-inflammatory short chain fatty acids (SCFAs), which may enhance leaky gut and gut dysbiosis through the dysfunction of intestinal barrier and the shortage of anti-bacterial peptides. Lower abundance of $7 \alpha$-dehydroxylating bacteria (Lachonospiraceae, Ruminococcaceae and Blautia) further lead to decrease in secondary bile acids (BAs), which may aggravate gut dysbiosis in American patients (B). As depicted in red, Veillonella, Megasphaera, Dialister, Atopobium and Prevotella were overrepresented in the duodenal mucosa of Chinese patients (A). The rectosigmoidal mucosal microbiome of American patients clearly showed a lower abundance of autochthonous genera (Dorea, Subdoligranulum and Incertae Sedis XIV other) and a higher abundance of potentially pathogenic ones (Enterococcus, Proteus, Clostridium and Burkholderia) (B, in red). Bacterial translocation and endotoxemia trigger liver and systemic inflammation, which eventually provokes various complications in liver cirrhosis. The microbial changes in patients with hepatic encephalopathy are shown in parentheses (A and $\mathbf{B})$.

Abbreviations: SIBO, small intestinal bacterial overgrowth; SIRS, systemic inflammatory response syndrome; SBP, spontaneous bacterial peritonitis. 


\section{Gut microbiome and metabolism}

Metagenomic and metabolomic analysis may be promising for evaluating the role of gut microbiome in host metabolism. However, reported data are still scarce and contradictory (Table 1). Metagenomic pyrosequencing of fecal microbiota has paved the way for the discovery of novel genes from uncultivated microorganisms, and the analysis of whole genomes from community DNA sequence data. ${ }^{29}$ Chen et al. $^{29}$ reported that patients with alcohol-related and HBVrelated cirrhosis showed marked depletion in the functional genes involved in nutrient processing, including amino acids, lipids and nucleotides metabolism. Qin et al. ${ }^{6}$ found that ammonia production and gamma-aminobutyric acid (GABA) biosynthesis were enriched in patients with liver cirrhosis by their comparative metagenomic analysis with gene functional classification, suggesting a potential role of gut microbiome in the development of HE. ${ }^{6}$

On the other hand, Wei et al. ${ }^{30}$ surprisingly found increased bacterial metabolic activities of carbohydrate, branched-chain amino acids, pantothenate and CoA with the progression of diseases from Child-Pugh class $A$ to class $C$ by their metaproteome analysis. They thought that the changes in cirrhotic intestinal microenvironment enhanced the growth and the protein expression of gut microbiome. The findings suggested that the fecal microbiome had robust adaptability to the intestinal microenvironment and could compensate for the innutritious body of cirrhotic patients. ${ }^{30}$ In line with this concept, the kind of bacteria responsible for the supposed metabolic compensation is of utmost importance. Their results are contradictory to the concept that gut bacterial changes cause metabolic disturbances in liver cirrhosis and arouse a question of whether we can really improve the metabolic state of cirrhotic patients by correcting gut dysbiosis.

\section{Microbial products and host reaction}

\section{Leaky gut and bacterial translocation}

The intestinal barrier consists of intestinal epithelial cells and their mucinous components. ${ }^{27}$ Intercellular junctions (i.e. tight junctions (TJs) and gap junctions) allow selective passage of substances. ${ }^{27}$ Structural and functional changes in the intestinal mucosa that enhance intestinal permeability are found in patients with liver cirrhosis. ${ }^{27}$ This intestinal barrier dysfunction is a dominant pathogenetic factor for several complications of liver cirrhosis. ${ }^{31}$ Alcohol drinking, portal hypertension, changes in gut microbiome, inflammation, oxidative stress and endotoxemia can all affect the barrier function of the intestine.

Several researchers ${ }^{32-35}$ have reported that patients with liver cirrhosis exhibit increased intestinal permeability, the state of so-called leaky gut. Intestinal hyperpermeability is associated with cirrhotics who have a history of $\mathrm{SBP}^{35}$ or severe liver disturbance, ${ }^{33-35}$ and is considered as a risk factor of bacterial infection. ${ }^{36}$ Expression of the TJ proteins occludin and claudin-1 in the duodenal mucosa was found to be reduced in cirrhotics, especially in those with ascites, and was correlated inversely with Child-Pugh score and endotoxemia. ${ }^{37}$ As copolymers of these proteins constitute the backbone of TJs in situ, it is plausible that these changes may be associated with disruption of the integrity of the intestinal barrier in cirrhotic patients. ${ }^{37}$
$\mathrm{BT}$, or microbial translocation, is defined as the migration of viable intestinal microorganisms or their products to the mesenteric lymph nodes (MLNs) or other extraintestinal sites. ${ }^{38}$ Passage of viable intestinal bacteria through the intestinal wall and their translocation to MLNs and other sites in liver cirrhosis is considered to provoke spontaneous infections such as SBP or bacteremia. ${ }^{27}$ Bacteria and their products translocate to extraintestinal sites and promote robust immunological responses. Pathological BT can predispose to complications of cirrhosis, not only infections but also other complications, by exerting an exacerbating effect on the immune system and hemodynamic state. ${ }^{27,39}$

\section{Endotoxin, bacterial DNA, Toll-like receptors (TLRs) and cirrhotic liver}

Plasma endotoxin levels are elevated with the progression of liver cirrhosis, ${ }^{40,41}$ and the elevation is also detectable in the portal blood. ${ }^{42,43}$ Bacterial DNA present in the portal and hepatic venous blood predisposes to a profound immune reaction in patients with advanced cirrhosis and ascites. ${ }^{44}$ Cirrhotic patients with translocated bacterial DNA of Grampositive taxa show increased pro-inflammatory cytokine levels unrelated to endotoxemia. ${ }^{45}$

Microbial products serving as pathogen-associated molecular patterns (PAMPs) bind to TLRs and activate the Kupffer cells, stimulating innate immune responses, such as excessive inflammatory cytokine production. Endotoxin binds to TLR4 and bacterial DNA containing unmethylated CpG-dinucleotides, activates TLR9. ${ }^{46}$ TLR2 recognizes lipoprotein and peptidoglycan of Gram-positive bacteria. ${ }^{47} \mathrm{Cir}-$ culatory inflammatory cytokines (i.e. tumor necrosis factor (TNF), IL-2, IL-4, IL-6 and IL-8) are increased especially in patients with alcohol-related cirrhosis or in those with massive ascites. ${ }^{48}$ Up-regulation of TLR2 and TLR4, and their pro-inflammatory mediators, activates hepatic stellate cells and enhances fibrosis, leading to the progression of liver cirrhosis and finally the development of hepatocellular carcinoma. ${ }^{49}$ On the contrary, TLR4 expression is downregulated in the peripheral blood mononuclear cells (PBMCs) of cirrhotics. ${ }^{50-52}$

A cytosolic multiprotein complex inflammasome is assembled upon recognition of PAMPs and accelerates inflammatory reactions by producing pro-inflammatory cytokines such as IL- $1 \beta$ and IL-18 through the activation of caspase- $1 .{ }^{53}$ In macrophages from ascitic fluid, one of the inflammasome components, AIM2 (the HIN-200 domain-containing protein absent in melanoma 2) pre-activated by bacterial DNA fragments, produces high levels of IL- $1 \beta$ and IL-18, which predispose to SBP in liver cirrhosis. ${ }^{53}$

\section{Gut impact on various cirrhotic complications}

\section{HE}

The mechanism of HE remains unclarified, although hyperammonemia and systemic inflammation related to gut dysbiosis have been proposed as contributors. ${ }^{54}$ Accumulating evidence indicates that systemic inflammation, neuroinflammation and endotoxemia play cardinal roles in the pathogenesis of HE. ${ }^{55-57}$ Endotoxin is known to increase permeability of the blood-brain barrier and to act on the brain microglia through endothelial cell receptors with the succeeding production of nitric oxide (NO) and prostanoid, ${ }^{57}$ 
Fukui H.: Microbiome-based therapeutics in cirrhosis

Table 1. Metagenomic and metabolomic analyses of fecal microbe in patients with liver cirrhosis

\begin{tabular}{|c|c|c|c|}
\hline & Subjects and methods & Main results & Suggestions \\
\hline Chen et al. $(2014)^{29}$ & $\begin{array}{l}\text { Subjects: } 12 \text { alcoholic } \\
\text { cirrhosis patients, } 18 \\
\text { HBV-related cirrhosis } \\
\text { patients, and } 12 \text { normal } \\
\text { controls. } \\
\text { Analytical methods: } \\
\text { Metagenomics. } \\
\text { Determination of the } \\
\text { functional structure of these } \\
\text { samples using a specific } \\
\text { functional gene array, which } \\
\text { is a combination of GeoChip } \\
\text { for monitoring } \\
\text { biogeochemical processes } \\
\text { and HuMiChip specifically } \\
\text { designed for analyzing } \\
\text { human microbiomes. }\end{array}$ & $\begin{array}{l}\text { The microbial community functional } \\
\text { composition and structure were distinctive } \\
\text { in alcoholic cirrhosis. Microbial functional } \\
\text { genes involved in organic remediation, } \\
\text { stress response, antibiotic resistance, metal } \\
\text { resistance and virulence were highly } \\
\text { enriched in the alcoholic cirrhosis group } \\
\text { compared to the control group and HBV- } \\
\text { related cirrhosis group. } \\
\text { The abundance of functional genes relevant } \\
\text { to nutrient metabolism, including amino } \\
\text { acid metabolism, lipid metabolism, } \\
\text { nucleotide metabolism and isoprenoid } \\
\text { biosynthesis, were significantly decreased } \\
\text { in patients with alcohol-related and } \\
\text { HBV-related cirrhosis. Significant } \\
\text { correlations were observed between } \\
\text { functional gene abundances and } \\
\text { Child-Pugh scores. }\end{array}$ & $\begin{array}{l}\text { Cirrhosis may have } \\
\text { distinct influence on } \\
\text { metabolic potential of } \\
\text { fecal microbial } \\
\text { communities. The } \\
\text { functional } \\
\text { composition of fecal } \\
\text { microbiomes was } \\
\text { heavily influenced by } \\
\text { cirrhosis, especially } \\
\text { by alcoholic cirrhosis. }\end{array}$ \\
\hline Qin et al. $(2014)^{6}$ & $\begin{array}{l}\text { Subjects: A total of } 123 \\
\text { patients with liver cirrhosis } \\
\text { and } 114 \text { healthy } \\
\text { counterparts of Han Chinese } \\
\text { origin. } \\
\text { Analytical methods: } \\
\text { Quantitative metagenomics } \\
\text { analysis developed by the } \\
\text { MetaHIT consortium. } \\
\text { Gene functional } \\
\text { classification and } \\
\text { orthologous group } \\
\text { abundance profiling. }\end{array}$ & $\begin{array}{l}\text { At the module or pathway level, the liver- } \\
\text { cirrhosis associated markers included } \\
\text { assimilation or dissimilation of nitrate to or } \\
\text { from ammonia, denitrification, GABA } \\
\text { ( } \gamma \text {-aminobutyric acid) biosynthesis, GABA } \\
\text { shunt, haem biosynthesis, } \\
\text { phosphotransferase systems and some } \\
\text { types of membrane transport, such as } \\
\text { amino-acid transport. (The control- } \\
\text { enriched modules included histidine } \\
\text { metabolism, ornithine biosynthesis, } \\
\text { creatine pathway, carbohydrate } \\
\text { metabolism, repair systems } \\
\text { and glycosaminoglycan } \\
\text { metabolism.) }\end{array}$ & $\begin{array}{l}\text { Enrichment of the } \\
\text { modules for ammonia } \\
\text { production and GABA } \\
\text { biosynthesis in } \\
\text { cirrhotic patients, } \\
\text { which suggests a } \\
\text { potential role of gut } \\
\text { microbiota in hepatic } \\
\text { encephalopathy. }\end{array}$ \\
\hline Wei et al. $(2016)^{30}$ & $\begin{array}{l}\text { Subjects: Three cirrhotic } \\
\text { patients with Child- } \\
\text { Turcotte-Pugh score of A, B } \\
\text { and C, and their spouse with } \\
\text { normal liver biochemistry. } \\
\text { Analytical methods: The } \\
\text { fecal metaproteome by the } \\
\text { high-throughput approach } \\
\text { based on denaturing } \\
\text { polyacrylamide gel } \\
\text { electrophoresis and liquid } \\
\text { chromatography-tandem } \\
\text { mass spectrometry } \\
\text { (LC-MS/MS). Functional } \\
\text { classification of identified } \\
\text { microbial proteins was } \\
\text { performed by BLASTPGP } \\
\text { searching against the } \\
\text { databases of Cluster of } \\
\text { Orthologous Groups } \\
\text { database. }\end{array}$ & $\begin{array}{l}\text { Expressions of } 14 \text { proteins related mainly to } \\
\text { carbohydrate transport and metabolism } \\
\text { were enhanced in patients with liver } \\
\text { cirrhosis compared with those in normal } \\
\text { controls. Especially the differences in } \\
\text { glyceraldehyde } 3 \text {-phosphate } \\
\text { dehydrogenase and glutamate } \\
\text { dehydrogenase were remarkable. } \\
\text { Expressions of } 7 \text { proteins were specific for } \\
\text { cirrhotic patients. As the CTP scores } \\
\text { increased, the number of specific enzymes } \\
\text { from two KEGG metabolic pathways (map } \\
00290 \text { related to branched-chain amino } \\
\text { acids biosynthesis and map 00770 related } \\
\text { to pantothenate and CoA biosynthesis) was } \\
\text { markedly increased in cirrhotic patients. }\end{array}$ & $\begin{array}{l}\text { As the patients' } \\
\text { conditions became } \\
\text { worse, fecal } \\
\text { microbiota showed } \\
\text { enhanced } \\
\text { biosynthetic abilities } \\
\text { of branched-chain } \\
\text { amino acid, } \\
\text { pantothenate, and } \\
\text { CoA, which are all } \\
\text { important in a wide } \\
\text { array of key and } \\
\text { essential biological } \\
\text { roles of life. The fecal } \\
\text { microbiota not only } \\
\text { had strong } \\
\text { adaptability to the } \\
\text { intestinal } \\
\text { microenvironment, } \\
\text { but also could } \\
\text { compensate for the } \\
\text { fragile and } \\
\text { innutritious body of } \\
\text { cirrhotic patients. }\end{array}$ \\
\hline
\end{tabular}


which may ultimately enhance the astrocyte swelling in $\mathrm{HE} .{ }^{58}$ Clinically, endotoxemia is associated with severity of minimal $\mathrm{HE}$ (MHE) and an increased incidence of overt HE. ${ }^{57}$ SIBO is closely related to $\mathrm{MHE}^{59}$ and the orocecal transit time (OCTT) is prolonged in cirrhotics with HE. ${ }^{60}$ Translocated bacterial DNA is considered to worsen neurocognitive scores in patients with MHE. ${ }^{61}$

Several studies have revealed altered gut microbiota in cirrhotic patients with HE. ${ }^{62}$ Liu et al. ${ }^{63}$ found an overgrowth of potentially pathogenic Escherichia coli (E. coli) and Staphylococcus spp. in the feces of patients with liver cirrhosis ( $70 \%-80 \%$ related to HBV or HCV) and MHE. Bajaj et al. ${ }^{11}$ showed that patients with cirrhosis and HE had a higher abundance of fecal Enterobacteriaceae, a known organism that produces potent endotoxin, ${ }^{26}$ and Alcaligenaceae compared with control subjects. Alcaligeneceae and Porphyromonadaceae were found to be positively correlated with cognitive impairment in patients with cirrhosis. Alcaligeneceae degrades urea to produce ammonia. ${ }^{11}$ Bajaj et al. ${ }^{18}$ next reported that cirrhotics with HE exhibited higher proportions of the potentially pathogenic genera Veillonella, Enterococcus, and Burkholderia and lower proportions of Roseburia in the colonic mucosa compared with those without $\mathrm{HE}$, while fecal microbiota was not different between the groups. Increases in potentially pathogenic bacteria (Enterococcaceae, Enterobacteriaceae) and decreases in autochthonous families were also found in the saliva of patients with previous history of HE. ${ }^{20}$ Ahluwalia et al. ${ }^{54}$ reported that fecal Enterobacteriaceae was positively correlated and autochthonous taxa was negatively correlated with hyperammonemiaassociated astrocytic changes on magnetic resonance spectroscopy and that Porphyromonadaceae was correlated with neuronal changes on diffusion tensor imaging.

\section{Infection}

Bacterial infections increase mortality 4-fold in cirrhotic patients. ${ }^{2}$ Although respiratory, urinary and ascitic fluid infections and bacteremia are common infectious complications of cirrhosis, SBP occurs most frequently. These infections are mostly related to enteric Gram-negative bacteria, mainly Enterobacteriaceae. ${ }^{3,64}$ Impaired motility of the small intestine and SIBO frequently occur in cirrhotic patients with a history of SBP. ${ }^{65}$ These patients commonly show increased intestinal permeability, ${ }^{35}$ which has been considered as a predictor of bacterial infection. ${ }^{36}$ Bacterial DNA was reported to be present in blood and ascites in one-third of cirrhotic patients with portal hypertension and culture-negative ascites. ${ }^{66}$ Presence of bacterial DNA is associated with increased pro-inflammatory cytokines in ascites, ${ }^{44}$ aggravation of peripheral vasodilation and worsening of intrahepatic endothelial dysfunction. ${ }^{67}$ Bacterial overgrowth predisposes to $\mathrm{BT}$ and increases the risk of SBP, together with intestinal hyperpermeability. ${ }^{68,69}$

There has been no direct evidence reported in the literature to prove the relationship of blood endotoxin to infection in liver cirrhosis. However, antibiotics (i.e. rifaximin) $)^{70}$ and probiotics (i.e. Lactobacillus $\mathrm{GG})^{71}$ have been shown to improve endotoxemia, exerting beneficial effects on hemodynamic, immunological and metabolic states in patients with advanced liver cirrhosis. There have also been scarce studies directed towards characterizing the changes in the intestinal microbiome of cirrhotic patients with SBP or sepsis.
Bajaj et al. ${ }^{17}$ found significant differences in the fecal microbiota (e.g., increased Enterobacteriaceae and decreased Coriobacteriaceae, Lachnospiraceae, Veillonellaceae and Clostridiales XIV), lower CDR and higher plasma endotoxin levels in cirrhotic patients admitted with infections compared with those without infections. In that study, routine culture detected Streptococcus spp., Klebsiella, Escherichia and Citrobacter spp. for SBP and E. coli, Enterococcus, Staphylococcus aureus and Lactococcus for urinary tract infections. ${ }^{17}$ Most bacteria causing SBP are Gram-negative bacilli, such as $E$. coli and other members of the Enterobacteriaceae family (Enterobacter, Klebsiella and Proteus), which are predominant in the gut microbiota of cirrhotic patients. ${ }^{5,7,11}$

\section{Hyperdynamic circulation}

Hyperdynamic circulation characterized by low systemic vascular resistance, high cardiac output and a reduced sensitivity to vasoconstrictors, are features of liver cirrhosis. ${ }^{3}$ A low systemic vascular resistance and a high cardiac output were more prominent in cirrhotics with endotoxemia than in those without endotoxemia. ${ }^{41}$ Oral administration of rifaximin was shown to improve the hyperdynamic circulation and endotoxemia. ${ }^{70}$ Further, the probiotic VSL\#3 was found to improve the hyperdynamic circulation in patients with liver cirrhosis. ${ }^{72}$ Although the role of endotoxin in the process of hyperdynamic circulation is still debatable, endotoxemia, possibly related to gut dysbiosis and leaky gut, may stimulate NO synthase, inducing increased vascular NO production, which is the primary force to evoke vasodilatation and its clinical manifestations in cirrhosis. ${ }^{73}$

\section{Portal hypertension and variceal bleeding}

Endotoxemia is also postulated to increase portal pressure ${ }^{74}$ and to induce variceal bleeding. ${ }^{75,76}$ It is plausible that endotoxin may elevate portal pressure by inducing systemic and splanchnic vasodilation, and by triggering hepatic inflammatory responses. ${ }^{3,74}$ It may increase portal vascular resistance through the cytokine-induced release of endothelin, NO and cyclooxygenase products in the liver. ${ }^{77-79}$ In turn, portal hypertension can promote BT and endotoxemia in patients with liver cirrhosis. ${ }^{74}$ Portal endotoxin level was decreased by the transjugular intrahepatic portosystemic shunt, suggesting that microbial translocation may be alleviated by the portal venous decompression. ${ }^{80}$ The effect of portal hypertension or portal venous decompression on gut microbiome has not been clarified yet.

Patients with cirrhosis and upper gastrointestinal hemorrhage have increased risk of bacterial infections, particularly SBP, during the first 7 days. ${ }^{81}$ Plasma endotoxin levels and intestinal permeability were reported to be increased after variceal hemorrhage. ${ }^{36,82}$ The latter was identified as an independent predictor for proven or possible infections by multivariate analysis. ${ }^{36}$ Prophylactic use of antibiotics can prevent infection and rebleeding and increase the short-term survival rate in patients with acute gastroesophageal variceal hemorrhage following endoscopic treatment. ${ }^{75,83}$

\section{Renal disturbance}

Hepatorenal syndrome (HRS) is a severe complication of patients characterized by a combination of systemic circulatory disturbance and renal dysfunction. Two types of HRS 
have been described: type 1 (a rapidly progressive acute renal failure, defined by a doubling of the initial serum creatinine level to greater than $2.5 \mathrm{mg} / \mathrm{dL}$ in less than 2 weeks) and type 2 (a slowly progressive moderate renal failure in patients with refractory ascites, showing initial serum creatinine level increase from 1.5 to $2.5 \mathrm{mg} / \mathrm{dL}$ ). ${ }^{84}$ International Club of Ascites recently imported a concept of acute kidney injury (AKI) and defined AKI in patients with cirrhosis as having an acute increase of serum creatinine to $\geq 50 \%$ from baseline to a final value $\geq 1.5 \mathrm{mg} / \mathrm{dl}$ ( $133 \mu \mathrm{mol} / \mathrm{L})$, aiming at early diagnosis and treatment of HRS. ${ }^{85}$

There has been a considerable debate surrounding the role of endotoxemia in the renal disturbance in cirrhosis. The close relationship suggested in the early period of Limulus amebocyte lysate (LAL) test ${ }^{86,87}$ was not always validated in the later period of quantitative LAL test. However, accumulating experimental evidence together with the observed beneficial effects of non-absorbable antibiotics support the pathogenetic roles of endotoxemia in the cirrhotic renal disturbance. ${ }^{88}$ Type 1 HRS often develops after a precipitating event, particularly SBP. ${ }^{1}$ Two-thirds of type- 1 HRS associated with infections is not reversible and exhibits very poor outcome. ${ }^{89}$ Cirrhotic patients with culture-negative, nonneutrocytic ascites and bacterial DNA have a higher risk of HRS, SBP and mortality compared with those without bacterial DNA. ${ }^{90}$

\section{Microbiome-based therapeutics}

\section{Probiotics}

Many studies have reported the effects of probiotics on HE and found that they are able to reduce blood ammonia levels, improve MHE and prevent overt HE. ${ }^{91}$ However, there exist other studies that deny these effects. Meta-analyses also have shown different conclusions. Shulka et al. ${ }^{92}$ reported that the administration of prebiotics, probiotics and synbiotics was related to improvement in MHE. Holte et al. ${ }^{93}$ concluded that probiotics and synbiotics improved HE more than placebo and lactulose. Xu et al. ${ }^{94}$ reported that probiotics reduced the incidence of overt HE. On the contrary, a Cochrane review by McGee et al. ${ }^{95}$ neglected the effects on the recovery from $\mathrm{HE}$ and the inhibition of $\mathrm{HE}$; they concluded that probiotics have no role in the treatment of MHE or HE. ${ }^{95}$ These meta-analyses have analyzed variable randomized controlled trials (RCTs) with different inclusion criteria, regimens and observation periods. More RCTs with ideal settings aiming for the determination of the ideal combination of organisms, optimal dose, optimal duration of treatment and benefits on long-term follow-up are necessary. Although two meta-analyses denied the effect of probiotics on overall survival, further careful evaluations are needed worldwide because almost all death cases have been reported from India. One study ${ }^{96}$ described that all patients who died were decompensated at baseline, irrespective of probiotic use. In another study, ${ }^{97}$ causes of death were acute variceal bleed, severe infection with sepsis, HRS, and intracranial bleed.

As for the relation of probiotics to gut microbiome, information is scarce in the previous reports. Bajaj et al. ${ }^{71}$ reported that probiotic Lactobacillus GG reduced relative abundance of Enterobacteriaceae and Porphyromonadaceae and increased beneficial autochthonous Lachnospiraceae and Clostridiales Incertae Sedis XIV in patients with stable cirrhosis and MHE. These microbial changes were further found to be related to alterations in metabolite/microbiome correlations associating with amino acid, vitamin and secondary BA metabolism and to decreases in blood endotoxin and TNF- $\alpha$ levels. As no specific change in fecal Lactobacillaceae was found, the authors speculated that Lactobacillus GG may induce the increase in other beneficial microbiota either by their mutual communication (quorum sensing) ${ }^{98}$ or by their promotion of epithelial function displacing pathogens and stimulating the host immune system. ${ }^{71}$

Recently, the effect of VSL\#3, a probiotic combination of eight strains of Lactobacilli, Bifidobacteria and Streptococcus, has been reported. Dhiman et al. ${ }^{99}$ found that VSL\# 3 reduced the incidence of hospitalization for HE and lowered Child-Pugh and MELD scores in cirrhotic patients who had completely recovered from an episode of overt HE. Lunia et al. ${ }^{97}$ reported that VSL\#3 administration for 3 months was effective in preventing $\mathrm{HE}$. It reduced arterial ammonia levels, ameliorated SIBO, shortened OCTT, and improved psychometric HE scores. Rincon et al. ${ }^{72}$ further reported that VSL\#3 decreased the hepatic venous pressure gradient, cardiac index and heart rate, and increased systemic vascular resistance in patients with cirrhosis and ascites. This suggests that VSL\# 3 improves the hepatic and systemic hemodynamics in advanced cirrhosis.

\section{Prebiotics and synbiotics}

The prebiotics are non-digestible food ingredients which selectively promote the growth of protective gut bacteria, such as Bifidobacteria and Lactobacilli, and increase the natural resistance to invading pathogens. ${ }^{100}$ They are resistant to gastric acidity but are susceptible to the metabolism by gut microbiota. ${ }^{100}$ At present, lactulose, lactitol, fructooligosaccharides (FOS) and galacto-oligosaccharides (GOS) are commercially available prebiotics. ${ }^{100}$ Among them, the synthetic disaccharides lactitol and lactulose have been used most widely in the treatment of HE. They remain undigested until they reach the large bowel, where they are metabolized by colonic bacteria and generate acetic and lactic acids. ${ }^{38}$ The resulting lower $\mathrm{pH}$ is considered to inhibit urease-producing bacteria and to promote the growth of nonurease-producing Lactobacilli. ${ }^{38,101}$ Chen et al. ${ }^{102}$ described that lactitol increased beneficial Bifidobacteria and Lactobacilli and decreased plasma endotoxin levels in patients with chronic viral hepatic diseases.

In contrast to these culture-based studies, Bajaj et al. ${ }^{17}$ reported an increase in dysbiosis, with lower CDR and higher abundance of Gram-negative bacteria (Enterobacteriaceae, Bacteroidaceae) despite lactulose administration in patients with $\mathrm{HE}$, which suggested that the effect of lactulose may not be attributable to improvement of dysbiosis. The underlying cirrhosis severity is possibly a stronger determinant of fecal microbial abundance pattern than the medication. ${ }^{17}$ Although a mixture of GOS and FOS were shown to increase Bifidobacteria in formula-fed infants in a manner similar to that of breast-fed infants, ${ }^{103}$ this combination has not been tried for patients with liver cirrhosis.

As a synbiotic regimen with Bifidobacterium longum, FOS was reported to be effective in the treatment of MHE. ${ }^{104}$ Synbiotic preparation consisting of four freeze-dried, non-ureaseproducing lactic acid bacteria and four fermentable fibers (Synbiotic $2000^{\circledR}$ ) was effective in cirrhotics with minimal HE. ${ }^{63}$ These patients were found to exhibit gut dysbiosis with significant fecal overgrowth of potentially pathogenic 
E. coli and Staphylococcal spp. Synbiotic treatment increased the fecal content of non-urease-producing Lactobacillus species, which was associated with a reduction in blood ammonia and endotoxin. ${ }^{63}$ An improvement in Child-Pugh class occurred in $47 \%$ of the patients who received synbiotic preparation, compared with $8 \%$ of the patients who received placebo. 63

Interestingly enough, this study further revealed that fermentable fiber alone was also of benefit in a substantial proportion of patients. ${ }^{63}$ Multivariate analysis showed that treatment with synbiotics or fermentable fiber alone was significantly related to resolution of $M H E{ }^{63}$ Malaguarnera et al. ${ }^{105}$ reported that the treatment with Bifidobacterium+ FOS represents an alternative to lactulose treatment in patients with cirrhosis, because its effects in reducing blood ammonia levels and in improving psychometric tests are rather superior to lactulose.

As described above, there is a great discrepancy between the remarkable effects of synbiotics and the controversial effects of probiotics on HE. Although further studies are needed, the substantial effects of either synbiotics or probiotics may have been related to the improvement of dysbiosis and/or metabolic derangement in the intestine. Metagenomic pyrosequencing of intestinal microbiota with an adequate metabolomic analysis may solve this problem.

\section{Antibiotics}

Selective intestinal decontamination (SID) for management of complications of liver cirrhosis has a long history with the use of various antimicrobial drugs, which have ranged from neomycin, polymixin $\mathrm{B}$ and paromomycin to norfloxacin and rifaximin. ${ }^{88}$ Long-term use of norfloxacin has been found to abolish aerobic Gram-negative bacilli from the feces, without significant effect on other microorganisms, and to reduce the recurrence of SBP. ${ }^{106}$ In cirrhotic patients with low ascitic fluid protein concentrations $(\leq 1 \mathrm{~g} / \mathrm{dL}$ ) or hyperbilirubinemia (> $2.5 \mathrm{mg} / \mathrm{dL}$ ), long-term prophylactic norfloxacin administration also prevented the first episode of SBP. ${ }^{107}$ However, these promising effects were challenged by the problem of quinolone-resistant infection. ${ }^{107,108}$ Prior antibiotic therapy and norfloxacin prophylaxis were shown to enhance the risk of infection by methicillin-resistant Staphylococcus aureus. ${ }^{109}$ Along this line, the primary prophylaxis of SBP with norfloxacin has been indicated only for high-risk cirrhotic patients.

Rifaximin, a minimally-absorbed oral antimicrobial agent, has broad-spectrum in vitro activity against Gram-positive and Gram-negative aerobic and anaerobic enteric bacteria, with little risk of inducing bacterial resistance. ${ }^{110}$ Its effect on advanced liver cirrhosis as an SID agent has been intensively studied. Accumulating evidence supports that it diminishes the risk of HE recurrence and HE-related hospitalizations. ${ }^{26}$ These studies further disclosed that rifaximin improves not only $\mathrm{HE}$ but also endotoxemia, ${ }^{111}$ systemic hemodynamics and renal function. ${ }^{70}$

Vlachogiannakos et al. ${ }^{111}$ reported that a 4 -week rifaximin regimen ameliorated endotoxemia and decreased the hepatic venous pressure gradient in patients with decompensated alcoholic cirrhosis. They later found that the long-term rifaximin administration reduced the risk of cirrhotic complications (variceal bleeding, SBP, HRS and HE) and improved the survival of patients with decompensated alcoholic cirrhosis. ${ }^{112}$ Kalambokis et al. ${ }^{70}$ noted that rifaximin treatment decreased cardiac output and increased systemic vascular resistance, glomerular filtration rate and natriuresis, in relation to suppression of plasma renin activity, and endotoxin, TNF- $\alpha$ and IL-6 levels. They further reported that rifaximin decreased neutrophil count in sterile ascites of cirrhotic patients ${ }^{113}$ and improved thrombocytopenia. ${ }^{114}$ Dănulescu et al. ${ }^{115}$ also reported that rifaximin decreased the incidence of SBP and improved survival in cirrhotic patients with refractory ascites.

Recently, the effect of rifaxmin on brain function has been investigated based on the concept of the gut-liver-brain axis. Bajaj et al. ${ }^{116}$ noted that rifaximin was associated with improvement of cognitive function and endotoxemia in patients with $\mathrm{MHE}$, which was accompanied by alterations of gut bacterial linkages with metabolites. No marked compositional changes in fecal microbiota were observed in the study, except for modest decrease in Veillonellaceae and increase in Eubacteriaceae. ${ }^{116}$ However, the overall network connectivity revealed that the positive correlation of Enterobacteriaceae, Porphyromonadaceae and Bacteroidaceae to products of aromatic amino acid and ammonia metabolism and oxidative stress indicators at baseline turned out to become negative correlation after rifaximin therapy, although the networks centered on autochthonous bacteria were not changed. ${ }^{116}$ The authors summarized that these pathogenic bacteria indicated a shift from pathogenic to beneficial metabolite linkages and better cognition after rifaximin therapy. ${ }^{116}$

The decrease of Veillonellaceae in the stool may be noteworthy, because it has been implicated in the pathogenesis of cirrhosis-associated inflammation. ${ }^{116}$ As for its relation to BA metabolism, rifaximin appears to suppress fecal DCA levels and alter the secondary/primary BA ratio in patients with compensated cirrhosis. DCA destabilizes the cell membranes of both intestinal epithelium and microbiome. ${ }^{26}$ Although decreased DCA favors the growth of pathogenic taxa, the direct antimicrobial effect of rifaximin may surpass it.

Ahluwalia et al. ${ }^{117}$ evaluated the effect of rifaximin on the gut-liver-brain axis in MHE by the use of functional magnetic resonance imaging, diffusion tensor imaging and magnetic resonance spectroscopy in an open-label study. Rifaximin was then demonstrated to improve cognition, including working memory performance and inhibitory control, and white matter integrity, through modulation of fronto-parietal and subcortical activation and connectivity in MHE. ${ }^{117}$ Dong et al. ${ }^{79}$ recently reported that long-term use of rifaximin decreased the incidence of AKI and HRS, and the need for renal replacement therapy in cirrhotic patients. The effect of rifaximin on other cirrhotic complications are now under investigation. ${ }^{26}$

\section{Unsolved problems in microbiome-based therapeutics}

The first important question is, if we can truly normalize the gut microbiome in patients with advanced liver cirrhosis. Although Bajaj et al. ${ }^{71}$ reported Lactobacillus GG improved gut dysbiosis of cirrhotic patients in association with alterations of metabolite/microbiome correlations, no other trials of probiotics have examined the gut microbial changes by the treatment. Although some authors have even denied the effects of probiotics on liver cirrhosis, it is not evident if their treatment protocols really improved gut dysbiosis or metabolic state. Future trials of probiotics, prebiotics and synbiotics are recommended to include metagenomic and/or 
metabolomic analysis for evaluation of their effects and their possible backgrounds.

Secondly, recent metagenomic studies revealed that the clinical effects of lactulose and rifaximin on HE may not be related to their effects on the population of gut microbiome but instead on their effects on bacterial function. ${ }^{17,116}$ Although these interesting findings show another theoretical ground to overcome gut dysbiosis in advanced liver cirrhosis, the mechanisms underlying how these medications improve the bacterial function or how the potentially pathogenic bacteria turn out to be innocuous or even beneficial are still quite unknown. To settle the controversy on the effect of lactulose, the implications of the culture method and metagenomic method in bacteriology should be carefully defined. In addition, further metagenomic and metabolomic analyses should be directed to the effects of prebiotics on cirrhotic patients.

Thirdly, the action mechanism of rifaximin is not completely understood, which may disturb the final settlement of its clinical indication. Emerging evidence in the studies on inflammatory bowel disease and irritable bowel syndrome also indicate that its function is not restricted to direct antibacterial effects. ${ }^{118}$ Its multifaceted function may include the reduction of bacterial virulence and pathogenicity by inhibiting BT and by modulating gut-immune signaling. The former is related to reduction in the release and/or absorption of endotoxin and bacterial products, and the latter probably depends on alterations of gene transcription that reduce or reverse the chronic proinflammatory response. ${ }^{118}$ Ongoing studies of rifaximin additionally include its effect on bacterial overgrowth and delayed intestinal transit. ${ }^{26}$ However, the overall clinical improvement without major alterations of gut dysbiosis found by Bajaj et al. ${ }^{116}$ may not be totally explained by these mechanisms. Alternatively, so far undetermined intestinal bacteriostatic condition or transformation of microbial function in the presence of rifaximin might underlie the effect. Mutual communications of gut microbe (quorum sensing) might be affected by rifaximin. Moreover, it is not still clear for whom rifaximin is most useful and recommended.

Finally, it should be answered if any combination of probiotics, prebiotics and rifaximin could improve the clinical situation more effectively. The improvement of gut dysbiosis and bacterial function is theoretically promising as final microbiome-based therapeutics.

\section{Conclusions}

More attention should be paid to the fact that the gut greatly impacts the clinical state of cirrhotic patients through gut dysfunction and dysbiosis, mobilizing the gut-liver axis profoundly. We are now beginning to understand that an adequate management of this gut-liver axis through microbiome-based therapeutics may have potential to improve a range of cirrhotic complications, mitigate annoying complaints, and ultimately prolong survival. Much should be examined in the future to explore an ideal strategy along these lines. Rapid progresses in metagenomic and metabolomic analyses, which can be further refined and unified, may finally enable us to evaluate the true function of gut microbiome as closely related to each patient's state. If we can adjust the gut-liver axis in the utmost interest of patients in the future, improving bacterial overgrowth, dysbiosis and leaky gut, we may even prolong the survival of patients with advanced cirrhosis.

\section{Conflict of interest}

The author has no conflict of interest related to this publication.

\section{Author contributions}

Collected all related information on the topic and wrote this review (HF).

\section{References}

[1] Fukui $H$, Saito $H$, Ueno $Y$, Uto $H$, Obara $K$, Sakaida $I$, et al. Evidence-based clinical practice guidelines for liver cirrhosis 2015. J Gastroenterol 2016;51: 629-650. doi: 10.1007/s00535-016-1216-y.

[2] Arvaniti V, D'Amico G, Fede G, Manousou P, Tsochatzis E, Pleguezuelo M, et al. Infections in patients with cirrhosis increase mortality four-fold and should be used in determining prognosis. Gastroenterology 2010;139: 1246-1256, 1256.e1-5. doi: 10.1053/j.gastro.2010.06.019.

[3] Fukui H. Gut microbiota and host reaction in liver diseases. Microorganisms 2015;3:759-791. doi: 10.3390/microorganisms3040759.

[4] Fukui $H$, Wiest R. Changes of intestinal functions in liver cirrhosis. Inflamm Intest Dis 2016;1:24-40. doi: 10.1159/000444436.

[5] Chen Y, Yang F, Lu H, Wang B, Chen Y, Lei D, et al. Characterization of fecal microbial communities in patients with liver cirrhosis. Hepatology 2011;54: 562-572. doi: 10.1002/hep.24423.

[6] Qin N, Yang F, Li A, Prifti E, Chen Y, Shao L, et al. Alterations of the human gut microbiome in liver cirrhosis. Nature 2014;513:59-64. doi: 10. 1038 /nature 13568

[7] Lu H, Wu Z, Xu W, Yang J, Chen Y, Li L. Intestinal microbiota was assessed in cirrhotic patients with hepatitis $B$ virus infection. Intestinal microbiota of HBV cirrhotic patients. Microb Ecol 2011;61:693-703. doi: 10.1007/ s00248-010-9801-8.

[8] Sokol H, Pigneur B, Watterlot L, Lakhdari O, Bermúdez-Humarán LG, Gratadoux JJ, et al. Faecalibacterium prausnitzii is an anti-inflammatory commensal bacterium identified by gut microbiota analysis of Crohn disease patients. Proc Natl Acad Sci U S A 2008;105:16731-16736. doi: 10.1073/pnas.0804812105.

[9] Xu M, Wang B, Fu Y, Chen Y, Yang F, Lu H, et al. Changes of fecal Bifidobacterium species in adult patients with hepatitis $B$ virus-induced chronic liver disease. Microb Ecol 2012;63:304-313. doi: 10.1007/s00248-011-9925-5.

[10] Wu ZW, Lu HF, Wu J, Zuo J, Chen P, Sheng JF, et al. Assessment of the fecal lactobacilli population in patients with hepatitis $B$ virus-related decompensated cirrhosis and hepatitis B cirrhosis treated with liver transplant. Microb Ecol 2012;63:929-937. doi: 10.1007/s00248-011-9945-1.

[11] Bajaj JS, Ridlon JM, Hylemon PB, Thacker LR, Heuman DM, Smith S, et al. Linkage of gut microbiome with cognition in hepatic encephalopathy. Am J Physiol Gastrointest Liver Physiol 2012;302:G168-G175. doi: 10.1152/ ajpgi.00190.2011.

[12] Wang HB, Wang PY, Wang X, Wan YL, Liu YC. Butyrate enhances intestinal epithelial barrier function via up-regulation of tight junction protein Claudin1 transcription. Dig Dis Sci 2012;57:3126-3135. doi: 10.1007/s10620012-2259-4.

[13] Willemsen LE, Koetsier MA, van Deventer SJ, van Tol EA. Short chain fatty acids stimulate epithelial mucin 2 expression through differential effects on prostaglandin $\mathrm{E}(1)$ and $\mathrm{E}(2)$ production by intestinal myofibroblasts. Gut 2003;52:1442-1447.

[14] Usami M, Miyoshi M, Yamashita H. Gut microbiota and host metabolism in liver cirrhosis. World J Gastroenterol 2015;21:11597-11608. doi: 10. 3748/wjg.v21.i41.11597.

[15] Corrêa-Oliveira R, Fachi JL, Vieira A, Sato FT, Vinolo MA. Regulation of immune cell function by short-chain fatty acids. Clin Transl Immunology 2016;5:e73. doi: 10.1038/cti.2016.17.

[16] Vinolo MA, Rodrigues HG, Nachbar RT, Curi R. Regulation of inflammation by short chain fatty acids. Nutrients 2011;3:858-876. doi: 10.3390/ nu3100858.

[17] Bajaj JS, Heuman DM, Hylemon PB, Sanyal AJ, White MB, Monteith P, et al. Altered profile of human gut microbiome is associated with cirrhosis and its complications. J Hepatol 2014;60:940-947. doi: 10.1016/j.jhep.2013.12. 019.

[18] Bajaj JS, Hylemon PB, Ridlon JM, Heuman DM, Daita K, White MB, et al. Colonic mucosal microbiome differs from stool microbiome in cirrhosis and hepatic encephalopathy and is linked to cognition and inflammation. Am J Physiol Gastrointest Liver Physiol 2012;303:G675-G685. doi: 10.1152/ ajpgi.00152.2012. 
[19] Chen $Y$, Ji F, Guo J, Shi D, Fang $D$, Li L. Dysbiosis of small intestinal microbiota in liver cirrhosis and its association with etiology. Sci Rep 2016;6: 34055. doi: 10.1038/srep34055.

[20] Bajaj JS, Betrapally NS, Hylemon PB, Heuman DM, Daita K, White MB, et al. Salivary microbiota reflects changes in gut microbiota in cirrhosis with hepatic encephalopathy. Hepatology 2015;62:1260-1271. doi: 10.1002/ hep. 27819.

[21] Betrapally NS, Gillevet PM, Bajaj JS. Gut microbiome and liver disease. Transl Res 2017;179:49-59. doi: 10.1016/j.trsl.2016.07.005.

[22] Kakiyama G, Pandak WM, Gillevet PM, Hylemon PB, Heuman DM, Daita K, et al. Modulation of the fecal bile acid profile by gut microbiota in cirrhosis. J Hepatol 2013;58:949-955. doi: 10.1016/j.jhep.2013.01.003.

[23] Kurdi P, Kawanishi K, Mizutani K, Yokota A. Mechanism of growth inhibition by free bile acids in lactobacilli and bifidobacteria. J Bacteriol 2006;188: 1979-1986. doi: 10.1128/JB.188.5.1979-1986.2006.

[24] Stenman LK, Holma R, Eggert A, Korpela R. A novel mechanism for gut barrier dysfunction by dietary fat: epithelial disruption by hydrophobic bile acids. Am J Physiol Gastrointest Liver Physiol 2013;304:G227-G234. doi: 10.1152/ajpgi.00267.2012.

[25] Islam KB, Fukiya S, Hagio M, Fujii N, Ishizuka S, Ooka T, et al. Bile acid is a host factor that regulates the composition of the cecal microbiota in rats. Gastroenterology 2011;141:1773-1781. doi: 10.1053/j.gastro.2011.07. 046.

[26] Bajaj JS. Review article: potential mechanisms of action of rifaximin in the management of hepatic encephalopathy and other complications of cirrhosis. Aliment Pharmacol Ther 2016;43 Suppl 1:11-26. doi: 10.1111/apt. 13435.

[27] Bellot P, Francés R, Such J. Pathological bacterial translocation in cirrhosis: pathophysiology, diagnosis and clinical implications. Liver Int 2013;33 31-39. doi: 10.1111/liv.12021.

[28] Ridlon JM, Alves JM, Hylemon PB, Bajaj JS. Cirrhosis, bile acids and gut microbiota: unraveling a complex relationship. Gut Microbes 2013;4 382-387. doi: 10.4161/gmic.25723.

[29] Chen Y, Qin N, Guo J, Qian G, Fang D, Shi D, et al. Functional gene arraysbased analysis of fecal microbiomes in patients with liver cirrhosis. BMC Genomics 2014;15:753. doi: 10.1186/1471-2164-15-753.

[30] Wei X, Jiang S, Chen Y, Zhao X, Li H, Lin W, et al. Cirrhosis related functionality characteristic of the fecal microbiota as revealed by a metaproteomic approach. BMC Gastroenterol 2016;16:121. doi: 10.1186/s12876-0160534-0.

[31] Kalaitzakis E. Gastrointestinal dysfunction in liver cirrhosis. World J Gastroenterol 2014;20:14686-14695. doi: 10.3748/wjg.v20.i40.14686

[32] Parlesak A, Schäfer C, Schütz T, Bode JC, Bode C. Increased intestinal permeability to macromolecules and endotoxemia in patients with chronic alcohol abuse in different stages of alcohol-induced liver disease. J Hepatol 2000;32:742-747. doi: 10.1016/S0168-8278(00)80242-1.

[33] Campillo B, Pernet $P$, Bories PN, Richardet JP, Devanlay M, Aussel C. Intestinal permeability in liver cirrhosis: relationship with severe septic complications. Eur J Gastroenterol Hepatol 1999;11:755-759. doi: 10.1097/ 00042737-199907000-00013.

[34] Pascual S, Such J, Esteban A, Zapater P, Casellas JA, Aparicio JR, et al. Intestinal permeability is increased in patients with advanced cirrhosis. Hepatogastroenterology 2003;50:1482-1486.

[35] Scarpellini E, Valenza V, Gabrielli M, Lauritano EC, Perotti G, Merra G, et al. Intestinal permeability in cirrhotic patients with and without spontaneous bacterial peritonitis: is the ring closed? Am J Gastroenterol 2010;105: 323-327. doi: 10.1038/ajg.2009.558.

[36] Kim BI, Kim HJ, Park JH, Park DI, Cho YK, Sohn CI, et al. Increased intestinal permeability as a predictor of bacterial infections in patients with decompensated liver cirrhosis and hemorrhage. J Gastroenterol Hepatol 2011;26 550-557. doi: 10.1111/j.1440-1746.2010.06490.x.

[37] Assimakopoulos SF, Tsamandas AC, Tsiaoussis GI, Karatza E, Triantos C, Vagianos $\mathrm{CE}$, et al. Altered intestinal tight junctions' expression in patients with liver cirrhosis: a pathogenetic mechanism of intestinal hyperpermeability. Eur J Clin Invest 2012;42:439-446. doi: 10.1111/j.1365-2362. 2011.02609.x.

[38] Pinzone MR, Celesia BM, Di Rosa M, Cacopardo B, Nunnari G. Microbial translocation in chronic liver diseases. Int J Microbiol 2012;2012:694629. doi: $10.1155 / 2012 / 694629$

[39] Pijls KE, Jonkers DM, Elamin EE, Masclee AA, Koek GH. Intestinal epithelial barrier function in liver cirrhosis: an extensive review of the literature. Liver Int 2013;33:1457-1469. doi: 10.1111/liv.12271.

[40] Fukui H, Tsujita S, Matsumoto M, Kitano H, Hoppou K, Morimura M, et al. Endotoxemia in chronic hepatitis and cirrhosis: Epiphenomenon or of pathological relevence? In: Blum H, Bode C, Bode JC, Sartor RB, eds. Gut and the Liver. Dordrecht, Boston, London: Kluwer Academic Publishers; 1998, p. 251-262.

[41] Lin RS, Lee FY, Lee SD, Tsai YT, Lin HC, Lu RH, et al. Endotoxemia in patients with chronic liver diseases: relationship to severity of liver diseases, presence of esophageal varices, and hyperdynamic circulation. J Hepatol 1995;22: 165-172. doi: 10.1016/0168-8278(95)80424-2

[42] Lumsden $A B$, Henderson JM, Kutner MH. Endotoxin levels measured by a chromogenic assay in portal, hepatic and peripheral venous blood in patients with cirrhosis. Hepatology 1988;8:232-236. doi: 10.1002/hep. 1840080207.

[43] Tachiyama G, Sakon M, Kambayashi J, Iijima S, Tsujinaka T, Mori T. Endogenous endotoxemia in patients with liver cirrhosis-a quantitative analysis of endotoxin in portal and peripheral blood. Jpn J Surg 1988;18:403-408. doi: 10.1007/BF02471464

[44] Francés R, González-Navajas JM, Zapater P, Muñoz C, Caño R, Pascual S et al. Translocation of bacterial DNA from Gram-positive microorganisms is associated with a species-specific inflammatory response in serum and ascitic fluid of patients with cirrhosis. Clin Exp Immunol 2007;150: 230-237. doi: 10.1111/j.1365-2249.2007.03494.x.

[45] González-Navajas JM, Bellot P, Francés R, Zapater P, Muñoz C, García-Pagán JC, et al. Presence of bacterial-DNA in cirrhosis identifies a subgroup of patients with marked inflammatory response not related to endotoxin. J Hepatol 2008;48:61-67. doi: 10.1016/j.jhep.2007.08.012.

[46] Rutz M, Metzger J, Gellert T, Luppa P, Lipford GB, Wagner H, et al. Toll-like receptor 9 binds single-stranded CpG-DNA in a sequence- and pH-dependent manner. Eur J Immunol 2004;34:2541-2550. doi: 10.1002/eji.200425218.

[47] Seki E, Schnabl B. Role of innate immunity and the microbiota in liver fibrosis: crosstalk between the liver and gut. J Physiol 2012;590:447-458. doi: 10.1113/jphysiol.2011.219691.

[48] Attar BM, George M, Ion-Nedelcu N, Ramadori G, Thiel DH. Disease dependent qualitative and quantitative differences in the inflammatory response to ascites occurring in cirrhotics. World J Hepatol 2014;6:85-91. doi: 10.4254/ wjh.v6.i2.85.

[49] Soares JB, Pimentel-Nunes P, Afonso L, Rolanda C, Lopes P, Roncon-Albuquerque $\mathrm{R} \mathrm{Jr}$, et al. Increased hepatic expression of TLR2 and TLR4 in the hepatic inflammation-fibrosis-carcinoma sequence. Innate Immun 2012 18:700-708. doi: 10.1177/1753425912436762.

[50] Manigold T, Böcker U, Hanck C, Gundt J, Traber P, Antoni C, et al. Differential expression of toll-like receptors 2 and 4 in patients with liver cirrhosis. Eur J Gastroenterol Hepatol 2003;15:275-282. doi: 10.1097/01.meg. $0000050010.68425 . \mathrm{cb}$.

[51] Riordan SM, Skinner N, Nagree A, McCallum H, McIver CJ, Kurtovic J, et al. Peripheral blood mononuclear cell expression of toll-like receptors and relation to cytokine levels in cirrhosis. Hepatology 2003;37:1154-1164. doi: 10.1053/jhep.2003.50180.

[52] Tazi KA, Quioc J], Saada V, Bezeaud A, Lebrec D, Moreau R. Upregulation of TNF-alpha production signaling pathways in monocytes from patients with advanced cirrhosis: possible role of Akt and IRAK-M. J Hepatol 2006;45: 280-289. doi: 10.1016/j.jhep.2006.02.013.

[53] González-Navajas JM. Inflammasome activation in decompensated liver cirrhosis. World J Hepatol 2016:8:207-210. doi: 10.4254/wjh v8.i4.207.

[54] Ahluwalia V, Betrapally NS, Hylemon PB, White MB, Gillevet PM, Unser AB, et al. Impaired gut-liver-brain axis in patients with cirrhosis. Sci Rep 2016; 6:26800. doi: $10.1038 /$ srep26800.

[55] Butterworth RF. Hepatic encephalopathy: a central neuroinflammatory disorder? Hepatology 2011;53:1372-1376. doi: 10.1002/hep.24228.

[56] Jain L, Sharma BC, Srivastava S, Puri SK, Sharma P, Sarin S. Serum endotoxin, inflammatory mediators, and magnetic resonance spectroscopy before and after treatment in patients with minimal hepatic encephalopathy. J Gastroenterol Hepatol 2013;28:1187-1193. doi: 10.1111/jgh. 12160.

[57] Luo M, Guo JY, Cao WK. Inflammation: A novel target of current therapies for hepatic encephalopathy in liver cirrhosis. World J Gastroenterol 2015; 21:11815-11824. doi: 10.3748/wjg.v21.i41.11815.

[58] Jayakumar AR, Rama Rao KV, Norenberg MD. Neuroinflammation in hepatic encephalopathy: mechanistic aspects. J Clin Exp Hepatol 2015;5:S21-S28. doi: 10.1016/j.jceh.2014.07.006.

[59] Gupta A, Dhiman RK, Kumari S, Rana S, Agarwal R, Duseja A, et al. Role of small intestinal bacterial overgrowth and delayed gastrointestinal transit time in cirrhotic patients with minimal hepatic encephalopathy. J Hepatol 2010;53:849-855. doi: 10.1016/j.jhep.2010.05.017.

[60] Van Thiel DH, Fagiuoli S, Wright HI, Chien MC, Gavaler JS. Gastrointestinal transit in cirrhotic patients: effect of hepatic encephalopathy and its treatment. Hepatology 1994;19:67-71.

[61] Moratalla A, Ampuero J, Bellot P, Gallego-Durán R, Zapater P, Roger M, et al. Lactulose reduces bacterial DNA translocation, which worsens neurocognitive shape in cirrhotic patients with minimal hepatic encephalopathy. Liver Int 2017;37:212-223. doi: 10.1111/liv.13200.

[62] Gómez-Hurtado I, Such J, Sanz Y, Francés R. Gut microbiota-related complications in cirrhosis. World J Gastroenterol 2014;20:15624-15631. doi: 10.3748/wjg.v20.i42.15624

[63] Liu Q, Duan ZP, Ha DK, Bengmark S, Kurtovic J, Riordan SM. Synbiotic modulation of gut flora: effect on minimal hepatic encephalopathy in 
patients with cirrhosis. Hepatology 2004;39:1441-1449. doi: 10.1002/ hep. 20194.

[64] Campillo B, Richardet JP, Kheo T, Dupeyron C. Nosocomial spontaneous bacterial peritonitis and bacteremia in cirrhotic patients: impact of isolate type on prognosis and characteristics of infection. Clin Infect Dis 2002;35: 1-10. doi: $10.1086 / 340617$.

[65] Chang CS, Chen GH, Lien HC, Yeh HZ. Small intestine dysmotility and bacterial overgrowth in cirrhotic patients with spontaneous bacterial peritonitis. Hepatology 1998;28:1187-1190. doi: 10.1002/hep.510280504.

[66] Such J, Francés R, Muñoz C, Zapater P, Casellas JA, Cifuentes A, et al. Detection and identification of bacterial DNA in patients with cirrhosis and culture-negative, nonneutrocytic ascites. Hepatology 2002;36:135-141. doi: $10.1053 /$ jhep.2002.33715.

[67] Bellot P, García-Pagán JC, Francés R, Abraldes JG, Navasa M, Pérez-Mateo $M$, et al. Bacterial DNA translocation is associated with systemic circulatory abnormalities and intrahepatic endothelial dysfunction in patients with cirrhosis. Hepatology 2010;52:2044-2052. doi: 10.1002/hep.23918.

[68] Aldersley MA, Howdle PD. Intestinal permeability and liver disease. Eur ] Gastroenterol Hepatol 1999;11:401-403. doi: 10.1097/00042737199904000-00007.

[69] Thalheimer U, Triantos CK, Samonakis DN, Patch D, Burroughs AK. Infection, coagulation, and variceal bleeding in cirrhosis. Gut 2005;54:556-563. doi: $10.1136 /$ gut.2004.048181.

[70] Kalambokis GN, Mouzaki A, Rodi M, Pappas K, Fotopoulos A, Xourgia X, et al. Rifaximin improves systemic hemodynamics and renal function in patients with alcohol-related cirrhosis and ascites. Clin Gastroenterol Hepatol 2012; 10:815-818. doi: 10.1016/j.cgh.2012.02.025.

[71] Bajaj JS, Heuman DM, Hylemon PB, Sanyal AJ, Puri P, Sterling RK, et al. Randomised clinical trial: Lactobacillus GG modulates gut microbiome, metabolome and endotoxemia in patients with cirrhosis. Aliment Pharmacol Ther 2014;39:1113-1125. doi: 10.1111/apt.12695.

[72] Rincón D, Vaquero J, Hernando A, Galindo E, Ripoll C, Puerto M, et al. Oral probiotic VSL\#3 attenuates the circulatory disturbances of patients with cirrhosis and ascites. Liver Int 2014;34:1504-1512. doi: 10.1111/liv. 12539.

[73] Rasaratnam B, Connelly N, Chin-Dusting J. Nitric oxide and the hyperdynamic circulation in cirrhosis: is there a role for selective intestinal decontamination? Clin Sci (Lond) 2004;107:425-434. doi: 10.1042/CS20040157.

[74] Trebicka J, Krag A, Gansweid S, Appenrodt B, Schiedermaier P, Sauerbruch $\mathrm{T}$, et al. Endotoxin and tumor necrosis factor-receptor levels in portal and hepatic vein of patients with alcoholic liver cirrhosis receiving elective transjugular intrahepatic portosystemic shunt. Eur J Gastroenterol Hepatol 2011;23:1218-1225. doi: 10.1097/MEG.0b013e32834a75dc.

[75] Hou MC, Lin HC, Liu TT, Kuo BI, Lee FY, Chang FY, et al. Antibiotic prophylaxis after endoscopic therapy prevents rebleeding in acute variceal hemorrhage: a randomized trial. Hepatology 2004;39:746-753. doi: 10 . 1002/hep. 20126.

[76] Lo RS, Austin AS, Freeman JG. Is there a role for probiotics in liver disease? Scientific World Journal 2014;2014:874768. doi: 10.1155/2014/874768.

[77] Pannen BH, Bauer M, Zhang JX, Robotham JL, Clemens MG. Endotoxin pretreatment enhances portal venous contractile response to endothelin-1. Am J Physiol 1996;270:H7-H15.

[78] Xu J, Cao H, Liu H, Wu ZY. Role of nitric oxide synthase and cyclooxygenase in hyperdynamic splanchnic circulation of portal hypertension. Hepatobiliary Pancreat Dis Int 2008;7:503-508.

[79] Dong T, Aronsohn A, Gautham Reddy K, Te HS. Rifaximin decreases the incidence and severity of acute kidney injury and hepatorenal syndrome in cirrhosis. Dig Dis Sci 2016;61:3621-3626. doi: 10.1007/s10620-0164313-0.

[80] Meng J, Wang Q, Liu K, Yang S, Fan X, Liu B, et al. Systemic and splanchnic lipopolysaccharide and endothelin-1 plasma levels in liver cirrhosis before and after transjugular intrahepatic portosystemic shunt. Gastroenterol Res Pract 2016;2016:8341030. doi: 10.1155/2016/8341030.

[81] Aguirre Valadez JM, Rivera-Espinosa L, Méndez-Guerrero O, ChávezPacheco JL, García Juárez I, Torre A. Intestinal permeability in a patient with liver cirrhosis. Ther Clin Risk Manag 2016;12:1729-1748. doi: 10. 2147/TCRM.S115902.

[82] Fukui H, Matsumoto M, Tsujita S, Takaya A, Kojima H, Matsumura M, et al. Plasma endotoxin concentration and endotoxin binding capacity of plasma acute phase proteins in cirrhotics with variceal bleeding: an analysis by new methods. J Gastroenterol Hepatol 1994;9:582-586. doi: 10.1111/j.14401746.1994.tb01565.x

[83] Bernard B, Grangé JD, Khac EN, Amiot X, Opolon P, Poynard T. Antibiotic prophylaxis for the prevention of bacterial infections in cirrhotic patients with gastrointestinal bleeding: a meta-analysis. Hepatology 1999;29: 1655-1661. doi: 10.1002/hep.510290608.

[84] Salerno F, Gerbes A, Ginès P, Wong F, Arroyo V. Diagnosis, prevention and treatment of hepatorenal syndrome in cirrhosis. Gut 2007;56:1310-1318. doi: 10.1136/gut.2006.107789.
[85] Angeli P, Ginès P, Wong F, Bernardi M, Boyer TD, Gerbes A, et al. Diagnosis and management of acute kidney injury in patients with cirrhosis: revised consensus recommendations of the International Club of Ascites. J Hepatol 2015;62:968-974. doi: 10.1016/j.jhep.2014.12.029.

[86] Clemente C, Bosch J, Rodés J, Arroyo V, Mas A, Maragall S. Functional renal failure and haemorrhagic gastritis associated with endotoxaemia in cirrhosis. Gut 1977;18:556-560. doi: 10.1136/gut.18.7.556.

[87] Wilkinson SP, Moodie H, Stamatakis JD, Kakkar VV, Williams R. Endotoxaemia and renal failure in cirrhosis and obstructive jaundice. Br Med J 1976;2: 1415-1418. doi: 10.1136/bmj.2.6049.1415.

[88] Fukui H. Gut-liver axis in liver cirrhosis: How to manage leaky gut and endotoxemia. World J Hepatol 2015;7:425-442. doi: 10.4254/wjh.v7.i3. 425.

[89] Barreto R, Fagundes C, Guevara M, Solà E, Pereira G, Rodríguez E, et al. Type-1 hepatorenal syndrome associated with infections in cirrhosis: natural history, outcome of kidney function, and survival. Hepatology 2014;59:1505-1513. doi: 10.1002/hep.26687.

[90] El-Naggar MM, Khalil el-SA, El-Daker MA, Salama MF. Bacterial DNA and its consequences in patients with cirrhosis and culture-negative, non-neutrocytic ascites. J Med Microbiol 2008;57:1533-1538. doi: 10.1099/jmm. 0.2008/001867-0.

[91] Sharma BC, Singh J. Probiotics in management of hepatic encephalopathy. Metab Brain Dis 2016;31:1295-1301. doi: 10.1007/s11011-016-9826-x.

[92] Shukla S, Shukla A, Mehboob S, Guha S. Meta-analysis: the effects of gut flora modulation using prebiotics, probiotics and synbiotics on minimal hepatic encephalopathy. Aliment Pharmacol Ther 2011;33:662-671. doi: 10.1111/j.1365-2036.2010.04574.x.

[93] Holte K, Krag A, Gluud LL. Systematic review and meta-analysis of randomized trials on probiotics for hepatic encephalopathy. Hepatol Res $2012 ; 42$ : 1008-1015. doi: 10.1111/j.1872-034X.2012.01015.x.

[94] Xu J, Ma R, Chen LF, Zhao LJ, Chen K, Zhang RB. Effects of probiotic therapy on hepatic encephalopathy in patients with liver cirrhosis: an updated metaanalysis of six randomized controlled trials. Hepatobiliary Pancreat Dis Int 2014;13:354-360. doi: 10.1016/S1499-3872(14)60280-0.

[95] McGee RG, Bakens A, Wiley K, Riordan SM, Webster AC. Probiotics for patients with hepatic encephalopathy. Cochrane Database Syst Rev 2011; (11):CD008716. doi: 10.1002/14651858.CD008716.pub2.

[96] Agrawal A, Sharma BC, Sharma P, Sarin SK. Secondary prophylaxis of hepatic encephalopathy in cirrhosis: an open-label, randomized controlled trial of lactulose, probiotics, and no therapy. Am J Gastroenterol 2012;107: 1043-1050. doi: 10.1038/ajg.2012.113.

[97] Lunia MK, Sharma BC, Sharma P, Sachdeva S, Srivastava S. Probiotics prevent hepatic encephalopathy in patients with cirrhosis: a randomized controlled trial. Clin Gastroenterol Hepatol 2014;12:1003-1008.e1. doi: 10.1016/j.cgh.2013.11.006.

[98] Lebeer S, De Keersmaecker SC, Verhoeven TL, Fadda AA, Marchal K, Vanderleyden J. Functional analysis of luxS in the probiotic strain Lactobacillus rhamnosus GG reveals a central metabolic role important for growth and biofilm formation. J Bacteriol 2007;189:860-871. doi: 10.1128/JB.01394-06.

[99] Dhiman RK, Rana B, Agrawal S, Garg A, Chopra M, Thumburu KK, et al. Probiotic VSL\#3 reduces liver disease severity and hospitalization in patients with cirrhosis: a randomized, controlled trial. Gastroenterology 2014;147:1327-1337.e3. doi: 10.1053/j.gastro.2014.08.031.

[100] Malaguarnera G, Giordano M, Nunnari G, Bertino G, Malaguarnera M. Gut microbiota in alcoholic liver disease: pathogenetic role and therapeutic perspectives. World J Gastroenterol 2014;20:16639-16648. doi: 10. 3748/wjg.v20.i44.16639.

[101] Riggio O, Varriale M, Testore GP, Di Rosa R, Di Rosa E, Merli M, et al. Effect of lactitol and lactulose administration on the fecal flora in cirrhotic patients. J Clin Gastroenterol 1990;12:433-436. doi: 10.1097/00004836199008000-00016.

[102] Chen C, Li L, Wu Z, Chen H, Fu S. Effects of lactitol on intestinal microflora and plasma endotoxin in patients with chronic viral hepatitis. J Infect 2007; 54:98-102. doi: 10.1016/j.jinf.2005.11.013.

[103] Bakker-Zierikzee AM, Alles MS, Knol ], Kok FJ, Tolboom J], Bindels JG. Effects of infant formula containing a mixture of galacto- and fructooligosaccharides or viable Bifidobacterium animalis on the intestinal microflora during the first 4 months of life. $\mathrm{Br}$ J Nutr 2005;94:783-790. doi: 10. 1079/BJN20051451.

[104] Malaguarnera M, Greco F, Barone G, Gargante MP, Malaguarnera M, Toscano MA. Bifidobacterium longum with fructo-oligosaccharide (FOS) treatment in minimal hepatic encephalopathy: a randomized, double-blind, placebocontrolled study. Dig Dis Sci 2007;52:3259-3265. doi: 10.1007/s10620006-9687-y.

[105] Malaguarnera M, Gargante MP, Malaguarnera G, Salmeri M, Mastrojeni S, Rampello $\mathrm{L}$, et al. Bifidobacterium combined with fructo-oligosaccharide versus lactulose in the treatment of patients with hepatic encephalopathy. Eur J Gastroenterol Hepatol 2010;22:199-206. doi: 10.1097/MEG. ob013e328330a8d3. 
[106] Ginés P, Rimola A, Planas R, Vargas V, Marco F, Almela M, et al. Norfloxacin prevents spontaneous bacterial peritonitis recurrence in cirrhosis: results of a double-blind, placebo-controlled trial. Hepatology 1990;12:716-724. doi: $10.1002 /$ hep.1840120416.

[107] Novella M, Solà R, Soriano G, Andreu M, Gana J, Ortiz J, et al. Continuous versus inpatient prophylaxis of the first episode of spontaneous bacterial peritonitis with norfloxacin. Hepatology 1997;25:532-536. doi: 10. 1002/hep.510250306.

[108] Fernández J, Navasa M, Gómez J, Colmenero J, Vila J, Arroyo V, et al. Bacterial infections in cirrhosis: epidemiological changes with invasive procedures and norfloxacin prophylaxis. Hepatology 2002;35:140-148. doi: 10. 1053/jhep.2002.30082.

[109] Campillo B, Dupeyron C, Richardet JP. Epidemiology of hospital-acquired infections in cirrhotic patients: effect of carriage of methicillin-resistant Staphylococcus aureus and influence of previous antibiotic therapy and norfloxacin prophylaxis. Epidemiol Infect 2001;127:443-450. doi: 10 . $1017 /$ S0950268801006288.

[110] Debbia EA, Maioli E, Roveta S, Marchese A. Effects of rifaximin on bacterial virulence mechanisms at supra- and sub-inhibitory concentrations. J Chemother 2008;20:186-194. doi: 10.1179/joc.2008.20.2.186.

[111] Vlachogiannakos J, Saveriadis AS, Viazis N, Theodoropoulos I, Foudoulis K, Manolakopoulos S, et al. Intestinal decontamination improves liver haemodynamics in patients with alcohol-related decompensated cirrhosis. Aliment Pharmacol Ther 2009;29:992-999. doi: 10.1111/j.1365-2036. 2009.03958.x.
[112] Vlachogiannakos J, Viazis N, Vasianopoulou P, Vafiadis I, Karamanolis DG, Ladas SD. Long-term administration of rifaximin improves the prognosis of patients with decompensated alcoholic cirrhosis. J Gastroenterol Hepatol 2013;28:450-455. doi: 10.1111/jgh.12070.

[113] Kalambokis GN, Mouzaki A, Rodi M, Tsianos EV. Rifaximin for the prevention of spontaneous bacterial peritonitis. World J Gastroenterol 2012;18: 1700-1702. doi: 10.3748/wjg.v18.i14.1700.

[114] Kalambokis GN, Mouzaki A, Rodi M, Tsianos EV. Rifaximin improves thrombocytopenia in patients with alcoholic cirrhosis in association with reduction of endotoxaemia. Liver Int 2012;32:467-475. doi: 10.1111/j.1478-3231. 2011.02650.x.

[115] Dănulescu RM, Ciobică A, Stanciu C, Trifan A. The role of rifaximine in the prevention of the spontaneous bacterial peritonitis. Rev Med Chir Soc Med Nat Iasi 2013;117:315-320.

[116] Bajaj JS, Heuman DM, Sanyal AJ, Hylemon PB, Sterling RK, Stravitz RT, et al. Modulation of the metabiome by rifaximin in patients with cirrhosis and minimal hepatic encephalopathy. PLoS One 2013;8:e60042. doi: 10. 1371/journal.pone.0060042.

[117] Ahluwalia V, Wade JB, Heuman DM, Hammeke TA, Sanyal AJ, Sterling RK, et al. Enhancement of functional connectivity, working memory and inhibitory control on multi-modal brain MR imaging with Rifaximin in Cirrhosis: implications for the gut-liver-brain axis. Metab Brain Dis 2014;29: 1017-1025. doi: 10.1007/s11011-014-9507-6.

[118] DuPont HL. Therapeutic effects and mechanisms of action of rifaximin in gastrointestinal diseases. Mayo Clin Proc 2015;90:1116-1124. doi: 10 1016/j.mayocp.2015.04.016. 